\title{
Deutscher Hausärztetag
}

\section{Politische}

\section{Langzeit-Strategie}

\begin{abstract}
Der Deutsche Hausärzteverband hat seine Argumentation für die Zeit des Bundestagswahlkampfes festgelegt. Angesichts der steigenden Unsicherheit im KV-System heißt es „Alles auf HZV". Eine Petition an den Bundestag soll das Thema noch in dieser Legislaturperiode auf die Agenda bringen; zudem sollen ProHZV-Parteien unterstützt werden. Alle Beschlüsse stehen in unserer Partner-Zeitschrift "Der Hausarzt".
\end{abstract}

Einmal im Jahr treffen sich die Delegierten des Deutschen Hausärzteverbandes zum Hausärztetag in Berlin. Dabei werden die wichtigen Pflöcke in den Boden gerammt, an denen der Vorstand sein berufspolitisches Engagement hochziehen kann. Auch in diesem Jahr gab es angeregte Diskussionen über die drängenden Themen. Das KV-System wurde angesichts der Honorarkrise - ein Beschluss des Erweiterten Bewertungsausschusses wurde von der KBV nicht akzeptiert - getadelt; die Hausarztzentrierte Versorgung (HZV) als einzige sinnvolle Alternative präsentiert.

In der Zeitschrift „Der Hausarzt“ können Sie dieses Mal die Beschlüsse der Delegierten nachschlagen. So unterstützen die Delegierten eine Petition des Bayeri- schen Hausärzteverbandes an den Bundestag, den berüchtigten Absatz 5a im $\$ 73 b$ SGB V zu streichen. Jener Absatz stellt HZV-Verträge unter eine Refinanzierungspflicht - und gräbt ihnen so das Wasser ab. Die Petition ist gewagt, weil es schwierig ist, breite Bevölkerungsanteile für ein Spezialthema aus dem Gesundheitssystem zu mobilisieren. Andererseits hat eine Bundestags-Petition gegen die Allgemeinen Kodierrichtlinien (AKR) diesen im letzten Jahr den Todesstoß verpasst - der Verband kann sich also auch Hoffnungen machen.

Hochinteressant ist auch ein weiterer politischer Beschluss der Delegierten: Sie beauftragen den Vorstand, eine Informationskampagne zum Wahljahr 2013 vorzubereiten. Die Bürger sollen über die
Hausärztechef Ulrich Weigeldt geißelte das KV-System.
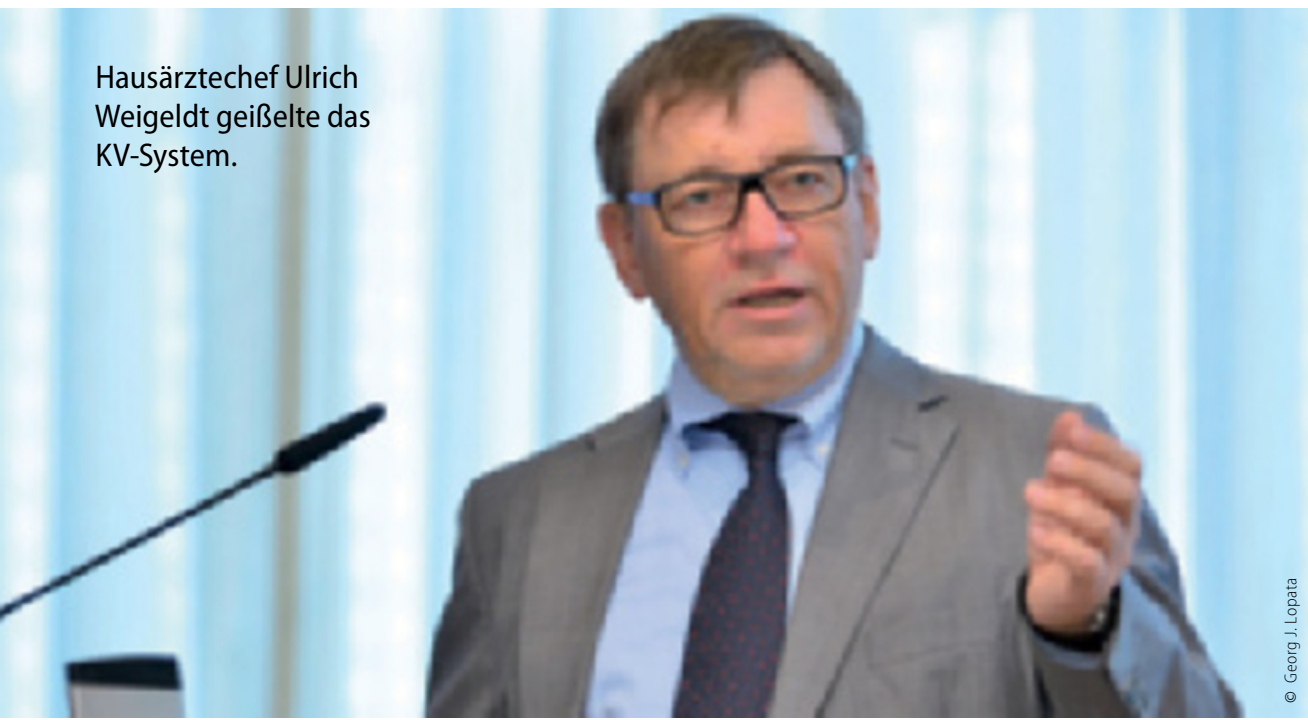

Konsequenzen des zunehmenden Hausarztmangels informiert werden - und über die mögliche Rettung in Form des alten $₫ 73 b$. Die Informationskampagne soll den Bürgern zudem jene Parteien nennen, die sich entschieden haben, den Hausarzt als ersten Ansprechpartner der Bürger bei gesundheitlichen Beschwerden zu retten. Soll heißen: Wer den alten $73 \mathrm{~b}$ wiederherstellen will, kann sich der Unterstützung des Hausärzteverbandes sicher sein. Genau dies ist aber Parteitagsbeschluss der SPD - und nur der SPD. Das geht schon in Richtung Wahlempfehlung; die schwarz-gelbe Bundesregierung hat sich beim Hausärzteverband wahrlich keine Freunde gemacht.

\section{Web-Hilfe zur Selbsthilfe}

HausMed ist eine neue Initiative des Hausärzteverbandes, um Compliance und gesunde Lebensführung der Patienten zu unterstützen. Mit Hilfe des Internets können Hausarzt und Patient sogenannte Coaches durchlaufen - Betreuungsprogramme, die den Patienten im Alltag begleiten und vom Arzt parallel überwacht werden können.

Immer mehr Hausärzte in Deutschland setzen die Coaches in der Praxis ein. Die HausMed-Gesellschaft hat nun erstmals eine Umfrage unter ihren Kunden durchgeführt und ist zu ermutigenden Ergebnissen gekommen. „Das Internet ermöglicht dem Patienten eine ganz neue Form des Selbstmanagements. Dadurch werden Gesunde und Patienten in Zukunft stärker Verantwortung für ihre Gesundheit übernehmen können - und müssen“, schreibt Geschäftsführer Florian Frensch in einem Beitrag im „Hausarzt“. Die traditionell enge Beziehung zwischen Arzt und Patient müsse aber auch weiterhin erhalten bleiben, das Internet werde komplementär eingesetzt und könne zu einer Verbesserung der Versorgung beitragen. Die interessanten Ergebnisse der Kundenumfrage gibt es im neuen „Hausarzt“. (Cornelius Heyer) 